\title{
Disruption in the automotive industry: A Cambrian moment
}

\section{Xavier Ferràs-Hernández *, Elisenda Tarrats-Pons, Núria Arimany-Serrat}

The University of Vic-Central University of Catalonia, Carrer de la Sagrada Familia 7, 08500 Vic, Barcelona, Spain

\author{
KEYWORDS \\ Automotive \\ innovations; \\ Cambrian moment; \\ Disruptive \\ technologies; \\ Global industries; \\ Creative destruction
}

\begin{abstract}
The automotive industry is experiencing a moment of innovation. With electronics gaining importance, the need to find sustainable solutions and the rampant availability of sharing platforms, the dynamics of this sector is witnessing a paradigm shift. A host of startups is colonizing every niche of what seems to be the new architecture: shared and self-driven electric vehicles. Old incumbents and emerging startups are interacting to control key technologies and the user interfaces of the future. The mechanical machine is being converted into a computer. The connected car is creating a new ecosystem for entrepreneurial opportunities. This study analyzes a set of 156 venture-backed startups: the nature of the firms, their founders' profiles, their origins, their technological capabilities, and their investors. Our findings and conclusions are: (1) a phase of instability and vibrancy is beginning wherein multiple emerging firms compete to impose their standards, (2) the competitive battle is conducted in the digital arena, (3) disruption is led by outsiders with entrepreneurial experience and deep knowledge of digital technologies, and (4) a final winning dominant design may emerge. Entrepreneurial outsiders and outsiders coming from consumer electronics, electrical companies, and/or digital platforms have a window of opportunity to enter this new market.

(C) 2017 Kelley School of Business, Indiana University. Published by Elsevier Inc. All rights reserved.
\end{abstract}

\section{The automotive industry: A Cambrian moment}

In January 2014, The Economist published an influential article titled "A Cambrian Moment," which

\footnotetext{
* Corresponding author

E-mail addresses: xavier.ferras@uvic.cat

(X. Ferràs-Hernández), elisenda.tarrats@uvic.cat

(E. Tarrats-Pons), nuria.arimany@uvic.cat (N. Arimany-Serrat)
}

explained a millisecond in time 540 million years ago when life forms began to multiply on earth. The article claimed that something similar is happening now in the economic world due to the force of disruptive new technologies. An entrepreneurial explosion fueled by technological change is transforming the foundations of almost every industry. Digital startups are spawning an astonishing variety of new products and business models. The disruption has hitherto penetrated a stable, oligopolistic industry dominated by a few big players that 
make up the automotive industry. Now, however, car manufacturing is going through its Cambrian moment.

With electronics gaining weight in the technological configuration of a car, along with the need for sustainable solutions and the emergence of sharing platforms, the dynamics of the whole sector is witnessing a paradigm shift. A host of new firms are invading the industry and colonizing every niche of what seems to be the new dominant design: shared, digital, and self-driven electric vehicles. A new era is beginning in which old mechanical incumbents fight against digital giants and emerging startups to control the key technologies of the future.

In this article, we aim to shed light on these startups and why and how they are threatening the very foundations of the old industry. To do so, we first carry out a literature review focused on how the combination of technological change and entrepreneurship creates new industry dynamics. Second, we provide an overview of what the automotive industry means in the global economy today, highlighting the evidence of a renewed entrepreneurial activity. We also analyze the most recent strategic consultancy reports and what scholars say about the current transformation in the industry. Third, we explore the features of a significant set of emerging technology startups to characterize who the new entrants are, in addition to their origins and competitive tools. Last, we show the results and discuss implications and further research avenues.

\section{How industries change: Theoretical foundations}

Several streams of researchers have analyzed the phenomenon of how an industry is transformed by emerging technologies and entrepreneurial initiatives. In such cases, new technologies are introduced into the market and create competitive destruction of the old (Schumpeter, 1942). Technological change has an unequivocal impact on economic growth (Solow, 1957; Tushman \& Anderson, 1986). Technological evolution is characterized by periods of great experimentation and entrepreneurial activity, followed by the acceptance of a new product architecture (Abernathy \& Utterback, 1978). Most of the fundamental innovations occur during the first years of an industry's existence when a stream of new entrants competes to impose their standards (Abernathy \& Clark, 1985). Researchers have characterized an architectural innovation as the case when new technologies make existing firms' competencies obsolete and create new market linkages, showing that competencedestroying technological waves are usually driven by new firms.

Foster (1988) introduced his famous S-curve model: A given technology is initiated with a phase of slow performance growth, followed by a quick expansion, and then finished with a maturity phase of limited improvement. Christensen (1997) demonstrated that first-movers and entrepreneurs enjoy a decided advantage over incumbents when a new product architecture is about to be born. He introduced the concept of disruptive innovation wherein an old company is overridden by new firms, moving away from immature (yet-to-be improved) technological capacities. It is not necessary for new firms to overcome the old firms' performance; it is enough to overcome the expectations of the old firms' market in some new dimensions of performance. Foster (1988) stated that new firms' strategic flexibility gives them a competitive advantage.

Spencer and Kirchhoff (2006) explored the link between technological change and creative destruction, with special attention to the role of new technology-based firms (NTBFs), showing that NTBFs are a leading driver of creative destruction. They described a set of advantages for NTBFs: low dependence on customers (since they do not yet have an existing customer base), low dependence on former investments, inexistence of organizational resistance to change, and rapid technological improvement (for they are operating before or during the S-curve slope). NTBFs ability to mobilize external resources (like venture capital) increases the possibility of bringing disruptions to the market (Rannikko, 2012). New firms have nothing to lose, while incumbents risk their current strategy, which has been successful so far.

\section{The present: An old fortress harassed by a swarm of technology-based startups}

\subsection{A true global industry}

The automotive industry is probably the best example of a truly international industry. It has been a generator and exporter of leading management practices and the source of a continuous stream of high and medium technologies. As stated by Bertoncello and Wee (2015), "as much as any other product, the car has shaped not only the global economy but how billions of people live." It has been a paradigm of an oligopolistic sector in which fierce competition has stimulated fast technology 
development. At a global level, the market has been traditionally dominated by the U.S., which in 1960 did about $75 \%$ of production worldwide. Today, China is the largest vehicle manufacturer, with a production rate of about 28 million yearly units, followed by the U.S. with about 12.2 million units.

The automotive sector has traditionally been a 'fortress-industry,' in that original equipment manufacturers (OEMs) hold a stable position with little chance of being displaced by entrepreneurs. When applying the five forces model (Porter, 1989), it was assumed that there was no possible substitute for the automobile-nothing offers the same level of convenience. The bargaining power of suppliers is low and buyers rely on big brands. Exorbitant investment capital is required to build manufacturing facilities prepared for global competition. The R\&D race in the industry is affordable only to gigantic producers. OEMs continue to focus on technological aspects in their fight for supremacy. Still today, it is an automotive company, Volkswagen, who holds the top R\&D budget in the world, with a total investment of $\$ 13.2$ billion (PricewaterhouseCoopers, 2017). No new entrepreneurs seem to be able to beat the big dinosaurs and the automobile's dominant architecture has not changed for more than a century.

Yet the time of stability is over. The first signs of disruption appeared with the emergence of Better Place, a startup founded in Palo Alto in 2007 by a charismatic entrepreneur, Shi Agassi, who promised to free the world of oil dependence through new electric vehicle batteries. The project attracted the interest of the Israeli government, which invited the company to establish operations in Israel. Agassi developed a new original business model: Vehicles would be sold without the battery, which would significantly reduce the price of the car. The battery would be owned by Better Place, and swapping battery stations would be deployed to change any exhausted battery in a few minutes. By 2011, the company had attracted more than $\$ 700$ million in venture capital. However, the huge investment required and a market share that was far lower than expected led Better Place to bankruptcy (Lunden, 2013). But the seed was sown. For the first time in a century, a young startup threatened to change the very economic foundations of the old fortress. Led by Tesla and Uber, a new wave of startups took over. Auto tech entrepreneurial dynamics heated up in 2016 when annual activity doubled to a record high, with over $\$ 1$ billion invested across 87 deals; this signified a tenfold increase in disclosed funding since 2012 (CB Insights, 2017). As the IBM Corporation noted, the industry is headed for major change: "For more than 100 years, the automotive industry has created competitive advantage through engineering excellence, but this will not be sufficient" (Wollshlaeger, Foden, Cave, \& Stent, 2015). Technology-driven trends like electric vehicles, data analytics, connectivity services, shared mobility, or autonomous cars will revolutionize the industry.

\subsection{What lies ahead: Sensing the winds of creative destruction}

Strategic consultants have performed intensive prospective analyses of the automotive market in the last few years, alerted by the impact of digitization in the car. KPMG and The Center for Automotive Research (2012) anticipated the convergence of sensor and communication technologies to create self-driving cars. The market seemed ready for the acceptance of autonomous cars (KPMG, 2013). The industry was crackling with entrepreneurship and was attracting some of the best and most creative thinkers, while billions of dollars in R\&D were being mobilized by venture capitalists (KPMG, 2014). Meanwhile, owning a car increasingly seemed an irrational decision. The average price of a new car was $\$ 31,253$ in 2013, an amount often unaffordable for individuals. In 2014, car sharing services attracted more than 1.2 million members in the U.S. alone (TSRC, n.d.).

A new ecosystem was being formed around traditional OEMs, new OEMs (like Tesla or Google), old suppliers, technology startups, venture capitalists, and research labs. Developing cutting-edge software and integrating the car with the smartphone ecosystem would be strategic differentiation factors for automotive leaders (Baker et al., 2016). McKinsey \& Company (2016) drafted four major trends for the automobile industry: (1) shifting revenue pools towards shared mobility; (2) changes in mobility behavior-10\% of the cars sold in 2030 could be shared vehicles; (3) diffusion of new technologies-15\% of the vehicles sold in 2030 could be autonomous; and (4) new competition and cooperation dynamics, with streams of new entrants targeting specific segments. Roland Berger (2016) forecasted that "completely new business models for automobile usage and ownership will emerge in the next ten years." KPMG (2016) said that "intelligent cars will demand smart business models." The new opportunities will expand revenue pools by about $30 \%$, up to $\$ 1.5$ trillion (McKinsey \& Company, 2016), and the scope of change will also affect cities. The transformation of the car into a mass-market mobility service could free up more than 5.7 billion square meters of parking space in the U.S. alone (Gao, Kass, Mohr, \& Wee, 2016). 


\subsection{What scholars know: A stock of knowledge ready to transform the market}

There is a wide stream of scientific literature around connected cars, autonomous vehicles, and electric vehicles. Yet this literature is found in very recent engineering journals and conferences. The abundance of technical research into new automobile systems anticipates the deep wave of business innovation that is coming. The car is being converted into a formidable sensor platform, a node of a new 'internet of vehicles' as an extension of the emerging internet of things (Gerla, Lee, Pau, \& Lee, 2014). The automotive industry is witnessing a paradigm shift and a profound change fueled by new technologies (i.e., self-driving systems, 3-D parts printing, new batteries), and by demographic trends (Swan, 2015). The automotive value chain has been converted into a cross-domain network of old manufacturers and smartphone manufacturers (Shelly, 2015). The car is being transformed into a big data orchestrator (Mikusz, Jud, \& Schäfer, 2015), which will likely be self-driven (Shapiro, 2016). We have found evidence of growth dynamics of NTBFs in the automotive industry, but the business transformation that this rapid technological change is creating has not yet been researched indepth by business scholars. We have found a dearth of management literature centered on this phenomenon. Our intention is therefore to fill part of this research gap. The next step is to identify which new firms are attacking the old fortress.

\section{Who the entrants are: Research questions and data collection}

Our research interests are focused on knowing the following questions: (1) What kind of companies are emerging in the industry? and (2) what is the origin of these companies? Principally, we intended to identify the profiles of these firms-whether they were founded by scientists, by experienced entrepreneurs, or by automotive managers, and in which of them old incumbents participate. With these goals in mind, we conducted an explorative study on the features of the emerging companies in the sector.

We obtained the study sample from Crunchbase, an international database of NTBFs, investors, and venture capital firms managed by the owners of TechCrunch, one of the most recognized international news outlets on technological innovation. The sample of companies was obtained by selecting the generic category 'automotive,' and the specific categories 'autonomous vehicles' and 'electrical vehicles.' We chose companies founded since January 2012, with headquarters in Europe and the U.S., and that have received a total funding amount greater than $\$ 100,000$. We consider that above this threshold, the quality of the companies is high enough, for they have proven to be attractive for professional investors, while below, their main financial sources are more likely 'fools, friends, and family.' The data were extracted on November 11, 2016. The initial sample consisted of 190 startups (eventually restricted to a pool of 156). The original database included the following information about the companies: description of the company, description of the product or service, technological competencies, fields of operation, website, date of foundation, total funding amount, and the list of investors.

After reviewing the company profiles and analyzing their websites, the companies were classified into 11 different groups according to the type of product/service they offered and their position in the value chain (see Figure 1). We excluded $26 \mathrm{com}$ panies from the sample after they were identified

Figure 1. Number of companies by type

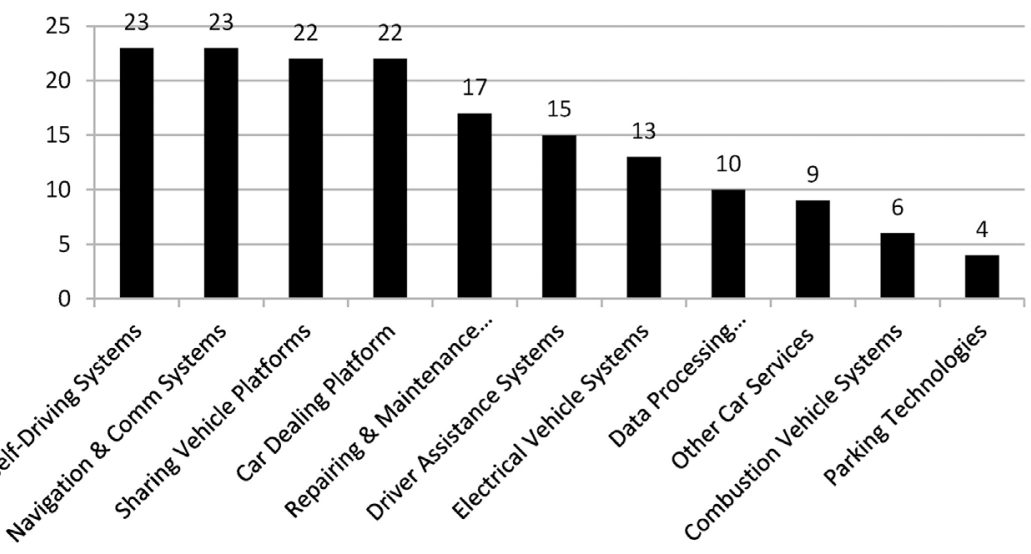


Figure 2. Funding amount by company

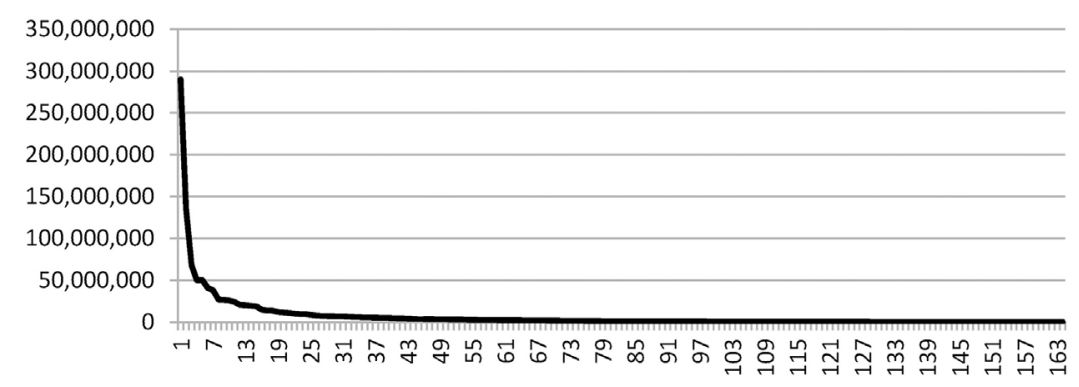

as manufacturers of other transport devices (motorcycles, bicycles, wheelchairs, or skates), financial firms, or companies not directly related to the sector. Based on this criteria, 164 companies emerged as valid. These companies accumulate an aggregated funding amount of approximately $\$ 1.2$ billion.

Figure 1 shows the distribution of companies by category. The largest categories are self-driving technologies, navigation and communication technologies, sharing vehicles platforms, and car dealer platforms. Companies are mainly in early funding rounds; 125 of the 164 companies $(76.21 \%)$ have obtained a total funding of less than $\$ 5$ million. Only two of them have received investments above $\$ 100$ million. Figure 2 shows the distribution of the total funding amounts along the series of companies and Figure 3 shows the segmentation of companies by investment ranges.

Of the 164, 109 companies $(66.46 \%)$ are North American-and of these, 52 (31.70\%) are headquartered in California. The most represented countries behind the U.S. are the U.K. (10 companies), the Netherlands ( 6 companies), Germany ( 5 companies) and France ( 5 companies). Figure 4 shows the number of companies by country of origin.

Figure 3. Number of companies by funding range

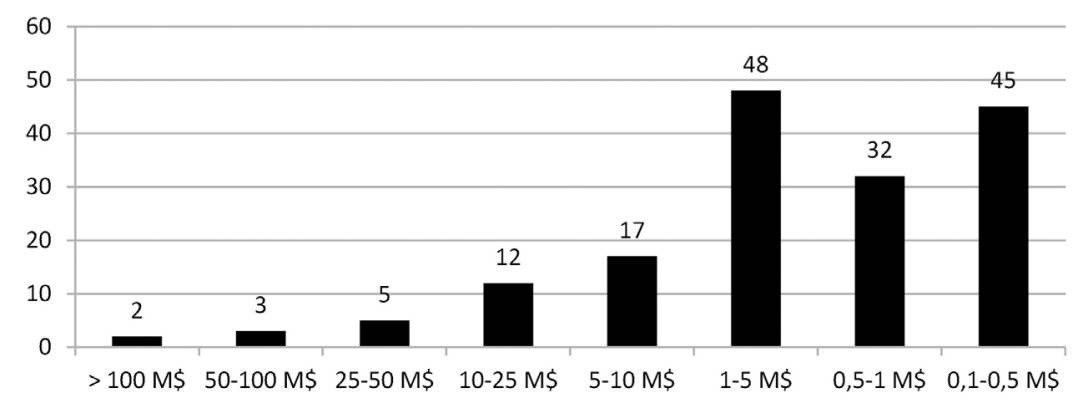

Figure 4. Number of companies by country

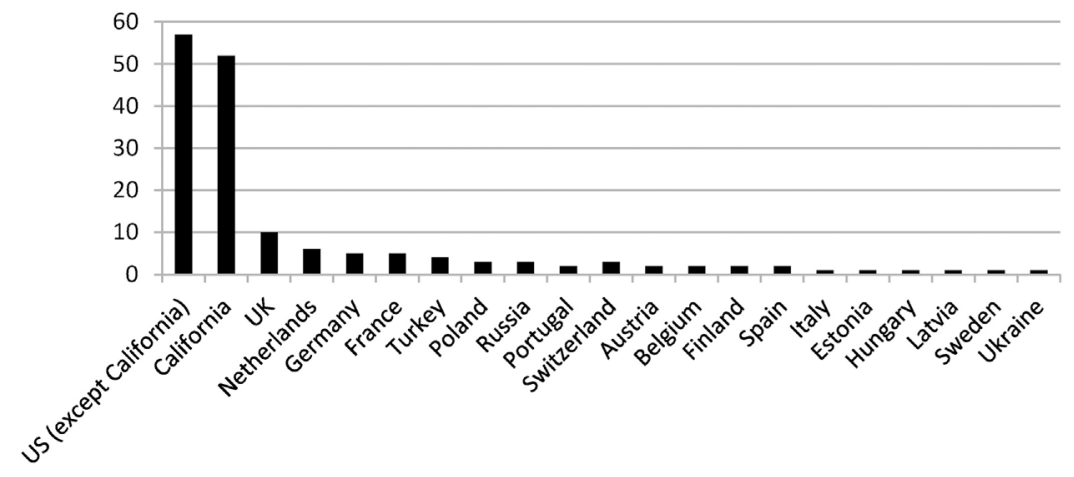




\section{In search of the origins: Scientific, entrepreneurial, or industrial founders?}

We completed the data collection exercise from Crunchbase with biographical information on the founding teams, extracted from the companies' websites. When no accurate information was found on the websites, we used the Linkedln profiles of the entrepreneurs. In 8 cases, we have not found any available biographical information. Therefore, there is a final sample of 156 companies with biographic information about their founders available.

Out of 156 companies in the sample, 35 (22.4\%) have founding teams with the presence of at least one $\mathrm{PhD}$, with a total of $49 \mathrm{PhDs}$ found. Of the remaining companies, 51 companies $(32.69 \%)$ have founding teams with at least one Master of Science degree (MSc). This means that a total amount of 86 (55\%) companies have scientists or high-tech professionals on their founding teams. The PhD programs in which the entrepreneurs participated correspond to studies in electrical engineering (15 cases), management and law (11 cases), computer sciences (10 cases), physics and mathematics (7 cases), bioengineering ( 3 cases), mechanical engineering ( 2 cases), and Aeronautics (1 case). Of the companies that do not have a PhD or MSc among their founders, 51 (32.69\%) have at least one university graduate. Among the founders with undergraduate degrees only, we identified degrees in management, economics, or marketing (42 cases); engineering or computer sciences ( 25 cases); and design or mechanical engineering ( 5 cases). Of the total sample, 19 firms (12.18\%) were created by entrepreneurs without a university degree.

In terms of experience in business creation, 87 out of $156(55.77 \%)$ companies include experienced entrepreneurs among their founders. The entrepreneurs with experience present in the founding teams of our sample have founded 366 companies (with an average of 3.85 companies founded per team). In 69 cases $(44.23 \%)$, the company in question is the first one founded by its team (no one from their team has previous entrepreneurial experience). With regard to prior experience in the automotive industry, only 39 out of 156 firms (25\%) have a founding team with at least one experienced manager coming from the industry.

In order to identify the most frequent profiles of the founding teams (technological/entrepreneurial/industry-experienced), we segmented the sample of companies according to their scientific and technological profiles (whether the founding teams have PhDs or MScs within their ranks), their entrepreneurial profiles (whether they have experienced entrepreneurs who previously have created other companies), and their level of industry experience (whether they have managers with specific experience in the automotive industry). Results can be seen in Table 1 .

If we analyze only those business categories related to advanced technologies, the proportion of management teams with PhDs increases-71 companies in the sample belong to the categories of self-driving systems, navigation and communication systems, data processing, and driver assistance systems. In two of them, we did not find biographical information for the founders. Of the remaining 69, 25 (36.23\%) have PhDs among their founders. The companies with PhDs or MScs on their founding teams reach $46(66.67 \%)$. As regards the entrepreneurial profiles, 39 (56.52\%) out of the 69 have founder teams with entrepreneurs who had already created other companies; and only 22 (31.88\%) have experienced automotive managers in the sector.

The composition of the founding teams changes substantially when we look at the category of sharing vehicles platforms. We did not find a single founding team with the presence of a PhD. Out of the 22 companies in this segment, $8(36.36 \%)$ have MScs on their founding teams, 12 (54.55\%) have

Table 1. Scientific/Entrepreneurial/Industryexperienced profiles present in the founding teams

\begin{tabular}{|c|c|c|c|c|}
\hline PhDs & Entrepreneurs & $\begin{array}{l}\text { Automotive } \\
\text { mgrs. }\end{array}$ & & \\
\hline No & No & No & 40 & $25.6 \%$ \\
\hline No & No & Yes & 16 & $10.2 \%$ \\
\hline No & Yes & No & 46 & $29.5 \%$ \\
\hline No & Yes & Yes & 19 & $12.2 \%$ \\
\hline Yes & No & No & 12 & $7.7 \%$ \\
\hline Yes & No & Yes & 2 & $1.3 \%$ \\
\hline Yes & Yes & No & 19 & $12.2 \%$ \\
\hline Yes & Yes & Yes & 2 & $1.3 \%$ \\
\hline & & Total & 156 & \\
\hline
\end{tabular}

\begin{tabular}{|c|c|c|c|c|}
\hline MSCS & Entrepreneurial & $\begin{array}{l}\text { Automotive } \\
\text { mgrs. }\end{array}$ & & \\
\hline No & No & No & 29 & $18.6 \%$ \\
\hline No & No & Yes & 11 & $7.1 \%$ \\
\hline No & Yes & No & 30 & $19.2 \%$ \\
\hline No & Yes & Yes & 13 & $8.3 \%$ \\
\hline Yes & No & No & 23 & $14.7 \%$ \\
\hline Yes & No & Yes & 7 & $4.5 \%$ \\
\hline Yes & Yes & No & 35 & $22.4 \%$ \\
\hline \multirow[t]{2}{*}{ Yes } & Yes & Yes & 8 & $5.1 \%$ \\
\hline & & Total & 156 & \\
\hline
\end{tabular}


experienced entrepreneurs but, again, only 3 $(13.64 \%)$ are founded by experienced managers in the automotive sector.

In the cases where entrepreneurs do not have previous experience in the automotive industry, we analyzed the fields of experience of the founders. Among the 117 founding teams with no experience in the industry, we found entrepreneurs who have declared experience in the following industries: technology (47 cases), software (43 cases), information technologies (32 cases), business management (22 cases), finance (21 cases), marketing (20 cases), telecommunications (18), electronics (14), internet (14), energy (13), web development (8), apps (6), aeronautics (4), and robotics (4).

Incumbents react through stake participations and acquisitions. Old leaders are taking positions in the capital of some of the emerging companies. Eleven of the sample companies are represented by OEMs or Tier 1 firms (BMW, General Motors, Toyota, Daimler, Jaguar Delphi, Vaelo, Magna, Faurecia and Robert Bosch are among their shareholders). Samsung is a shareholder of three other startups, and Microsoft has invested in two of them. One firm, Ottomatika, was acquired by Delphi in 2015 (for a nondisclosed amount) and another, Cruise Automation, by General Motors in 2016 (for $\$ 581$ million).

\section{Summary: The revolution is led by outsiders}

We analyzed emerging technology-based companies in the automotive industry using Crunchbase's database. We studied the profiles of their founding teams in search of the origin of these companies. We found that the categories of greater presence are those of self-driving systems, navigation \& communication systems and Vehicle-sharing platforms. Confirming the research findings of major consultancy firms, the sector seems to be heading toward a new paradigm of self-driven, connected and shared vehicles.

With regard to the backgrounds of founding members, $62.82 \%$ of emerging companies have at least one member with a PhD or MSc. PhDs have been mostly pursued in electrical engineering and computer science. Experienced entrepreneurs participated in $55.77 \%$ of the sample companies, with most of them having experience in fields related to technology, software, and information systems. However, only 39 of the 156 companies analyzed $(25 \%)$ have experienced managers from the automotive industry among their founders. The proportion of $\mathrm{PhDs}$ and MScs increases in those categories related to autonomous driving technologies, navigation, driving assistance systems, and connected vehicles, and decreases in those related to vehicle-sharing business models. The emerging company profile, therefore, is characterized by founding teams with advanced knowledge or experience in electronic engineering, software, or computer sciences.

Experience in the industry specifically does not seem to be a decisive factor in founding a promising emerging automobile company. The automotive value chain, which has traditionally been closed by incumbents, is becoming a value chain open to digital experts. The revolution is led by outsiders with entrepreneurial experience and deep knowledge of electrical engineering and software, capacities that have been external or secondary in a basically mechanical industry. Digital technologies have therefore opened the door for entrepreneurs to conquer the new automotive value chain; the entrance to the old impregnable fortress has fallen, giving rise to new business models built around collaborative digital platforms, intelligent algorithms, big data, and next-generation sensors. The future superstars of this new automotive model are being designed today by entrepreneurs in some remote garage. Venture capitalists know this and are starting to make serious bets.

\section{Further discussions and management implications}

A phase of instability and effervescence is beginning in the industry, triggered by accelerated technological change. Multiple firms-incumbents and new entrants-will compete to impose their standards, destroying the oligopolistic balance enjoyed to date. Car design and manufacturing is entering an era of product innovation wherein the concept of the vehicle will be redefined based on the new features offered by digital technologies. Given the diversity of emerging technologies in the sample of firms, it seems that there is no definitive technological standard yet. A vertical/integral industry seems to be disintegrating and is becoming horizon$\mathrm{tal} /$ modular, but this cycle is usually followed by the apparition of new big players that will expand vertically again, in a sort of clock-speed cycle (Fine, 2000). The critical role of safety and vehicle-tovehicle communications, which require compatibility assurance between brands as a must, anticipates a winner-takes-all-dynamic, as is often the case in digital markets (Varian \& Shapiro, 1998) like what happened in the 1980s with the IBM PC and the 'Wintel' standard (Windows + Intel). Indeed, the struggle for the imposition of standards has already 
begun with the aggressive strategic movement of Tesla giving away their patents as if they were open source (Chambers, 2014). The movement is almost identical to IBM's in the 1980s, when-in the face of fierce competition with many brands with noncompatible technologies trying to impose their standards-IBM opened its design with the intention of making it the industry's dominant architecture. It did so but at the price of commoditizing a high-tech product like the $P C$, which became a low-cost object. IBM PC clones spread throughout the world and the IBM PC standard dominated the industry for almost 20 years. In the automotive industry, this dynamic may be repeated. A winner-takes-all game may emerge. Once that happens, the window of opportunity for entrepreneurs will be closed again.

The industry is being redefined. The competitive battle will be conducted in the digital arena. As we have seen, entrepreneurs with deep knowledge or experience in digital markets or electronics have an opportunity in the new ecosystem. Additionally, companies coming from industrial or consumer electronics industries, electrical companies, and/ or interactive digital platforms may also have a huge opportunity to exploit their expertise and enter this new market.

\section{References}

Abernathy, W. J., \& Clark, K. B. (1985). Innovation: Mapping the winds of creative destruction. Research Policy, 14(1), 3-22.

Abernathy, W. J., \& Utterback, J. M. (1978). Patterns of industrial innovation. Technology Review, 80(7), 40-47.

Baker, E. H., Crusius, D., Fisher, M., Gerling, W., Gnanaserakan, H., Kerstan, H., et al. (2016). Connected car report. Available at http://www.strategyand.pwc.com/media/file/ Connected-car-report-2016.pdf

Bertoncello, M., \& Wee, D. (2015, June). Ten ways autonomous driving could redefine the automotive world. Available at http: / / www. mckinsey.com/industries/automotive-andassembly/our-insights/ten-ways-autonomous-driving-couldredefine-the-automotive-world

CB Insights. (2017, January 12). Auto tech startup financing tops $\$ 1$ billion in 2016. Available at https: / /www.cbinsights.com/ blog/auto-tech-startups-2016-recap/

Chambers, C. (2014, June 13). Tesla giving away its patents makes sense. Forbes. Available at https://www.forbes. com/sites/investor/2014/06/13/tesla-giving-away-itspatents-makes-sense/\#5e1d454013ea

Christensen, C. M. (1997). The innovator's dilemma: When new technologies cause great firms to fail. Brighton, MA: Harvard Business Review Press.

Fine, C. H. (2000). Clockspeed-based strategies for supply chain design. Production and Operations Management, 9(3), 213-221.

Foster, R. N. (1988). Innovation: The attacker's advantage. New York: Simon \& Schuster.

Gao, P., Kass, H-W., Mohr, D., \& Wee, D. (2016, January). Disruptive trends that will transform the auto industry.
Available at http://www.mckinsey.com/industries/hightech/our-insights/disruptive-trends-that-will-transformthe-auto-industry

Gerla, M., Lee, E. K., Pau, G., \& Lee, U. (2014). Internet of vehicles: From intelligent grid to autonomous cars and vehicular clouds. In 2014 IEEE World Forum on Internet of Things (pp. 241-246). Piscataway, NJ: IEEE.

KPMG. (2013). Self-driving cars: Are we ready? [White paper]. Available at http://docplayer.net/33713-Self-driving-carsare-we-ready-kpmg-com.html

KPMG. (2014). Me, my car, my life . . . In the ultra-connected age [White paper]. Available at https://assets.kpmg.com/ content $/ \mathrm{dam} / \mathrm{kpmg} / \mathrm{pdf} / 2014 / 11 / \mathrm{me}$-my-life-my-car.pdf

KPMG. (2016). Intelligent cars demand smart business models. Available at https://assets.kpmg.com/content/dam/kpmg/ $\mathrm{uk} / \mathrm{pdf} / 2016 / 11 /$ open-minds-smart-car-smart-businessmodel.pdf

KPMG \& The Center for Automotive Research. (2012). Selfdriving cars: The next revolution [White paper]. Available at https://faculty.washington.edu/jbs/itrans/self_driving cars[1].pdf

Lunden, I. (2013, July 12). A new place for Better Place, as bankrupt $\$ 800 \mathrm{M}+$ backed electric car startup sold for $\$ 12 \mathrm{M}$. TechCrunch. Available at https://techcrunch.com/2013/07/ 12/a-new-place-for-better-place-as-bankrupt-800mbacked-electric-car-startup-sold-for-12m/?ncid=tcdaily

McKinsey \& Company. (2016, January). Automotive revolutionPerspective towards 2030. Available at https://www. mckinsey.de/files/automotive_revolution_perspective towards_2030.pdf

Mikusz, M., Jud, C., \& Schäfer, T. (2015). Business model patterns for the connected car and the example of data orchestrator. In J. Fernandes, R. Machado, \& K. Wnuk (Eds.), Software Business: $6^{\text {th }}$ International Conference, ICSB 2015 (pp. 167173). New York: Springer.

Porter, M. E. (1989). From competitive advantage to corporate strategy. In D. Asch \& C. Bowman (Eds.), Readings in strategic management (pp. 234-255). London: Macmillan Education.

PricewaterhouseCoopers. (2017). 2016 Global Innovation 1000 study. Available at https://www.strategyand.pwc. com/innovation 1000

Rannikko, H. (2012). Early development of new technologybased firms: A longitudinal analysis on new technologybased firms' development from population level and firm level perspectives. Helsinki: Hanken School of Economics.

Roland Berger. (2016). Global automotive supplier study 2016. Available at https://www.rolandberger.com/publications/ publication_pdf/roland_berger_global_automotive_ supplier_2016_final.pdf

Schumpeter, J. (1942). Capitalism, socialism, and democracy. New York: Harper \& Brothers.

Shapiro, D. (2016). Accelerating the race to autonomous cars. In Proceedings of the $22^{\text {nd }}$ ACM SIGKDD International Conference on Knowledge Discovery and Data Mining (p. 415). New York: ACM.

Shelly, P. (2015). Addressing challenges in automotive connectivity: Mobile devices, technologies, and the connected car. SAE International Journal of Passenger Cars-Electronic and Electrical Systems, 8(1), 161-169.

Solow, R. M. (1957). Technical change and the aggregate production function. The Review of Economics and Statistics, 39(3), 312-320.

Spencer, A. S., \& Kirchhoff, B. A. (2006). Schumpeter and new technology based firms: Towards a framework for how NTBFs cause creative destruction. International Entrepreneurship and Management Journal, 2(2), 145-156. 
Swan, M. (2015). Connected car: Quantified self becomes quantified car. Journal of Sensor and Actuator Networks, 4(1), 2-29.

TSRC. (n.d.). Carsharing. Available at http://tsrc.berkeley.edu/ carsharing

Tushman, M. L., \& Anderson, P. (1986). Technological discontinuities and organizational environments. Administrative Science Quarterly, 31(3), 439-465.
Varian, H. R., \& Shapiro, C. (1998). Information rules: A strategic guide to the network economy. Brighton, MA: Harvard Business Review Press.

Wollshlaeger, D., Foden, M., Cave, R., \& Stent, M. (2015). Digital disruption and the future of the automotive industry. IBM Corporation. Available at https://www-935.ibm. com/services/multimedia/IBMCAl-Digital-disruption-inautomotive.pd 